Bangladesh J. Genet PI. Breed: 20(2): 37-41, 2007

\title{
GENETIC DIVERGENCE IN DOUBLED HAPLOID LINES OF SPRING WHEAT
}

(Triticum aestivum L.)

\author{
M. M. Rahman', A. K. M. Shamsuddin' ${ }^{2}$ U. Asad ${ }^{3}$ and S. M. N. Islam ${ }^{4}$ \\ Department of Genetics and Plant Breeding \\ Bangladesh Agricultural University \\ Mymensingh 2202, Bangladesh
}

\begin{abstract}
Genetic divergence of 17 doubled haploid lines and 3 check varieties of spring wheat were assessed through Mahalanobis' $\mathrm{D}^{2}$-statistics. The genotypes were grouped into six clusters. The clusters I and III contained the highest number of lines (5). The cluster $\mathrm{V}$ contained single genotype. The maximum inter-cluster distance was noticed between the clusters I and V and minimum between III and VI. The highest intra-cluster distance was observed in the cluster IV and lowest in the cluster V.
\end{abstract}

Key words: Wheat (Triticum aestivum L.), genetic diversity, doubled haploid

\section{INTRODUCTION}

Assessment on genetic diversity among the genotypes is important for planning an effective breeding program as the genetically diversed genotypes are known to produce high heterotic effects and result desirable segregants for developing high yielding varieties. It has become possible to quantify magnitude of genetic diversity among germplasm with the help of advanced biometrical method, such as multivariate analysis (Rao, 1952) based on Mahalanobis' (1936) D ${ }^{2}$-statistics. A number of doubled haploid lines in wheat were developed in the Department of Genetics and Plant Breeding, Bangladesh Agricultural University, Mymensingh through a USDA financed project "Production of haploid through wheat $\times$ maize cross and their utilization in wheat improvement". These lines need assessment of variation among them for evaluation of their potentiality in breeding program. Multivariate approaches of analysis of variation among the lines were done with this view.

\section{MATERIALS AND METHODS}

Twenty genotypes of wheat (Triticum aestivum L.) including 17 double haploid (DH) lines (DH-1, DH-2, DH-3, DH-4, DH-5, DH-6, DH-7, DH-8, DH-9, DH-10, DH-11,

\footnotetext{
${ }^{1}$ Pulses Research Centre, Regional Agricultural Research Station, Isurdi, Pabna; ${ }^{2}$ Department of Genetics and Plant Breeding, Bangladesh Agricultural University, Mymensingh 2202; ${ }^{3}$ Oilseed Research Centre, Regional Agricultural Research Station, Isurdi, Pabna; and ${ }^{4}$ Department of Biotechnology, Bangladesh Agricultural University, Mymensingh 2202, Bangladesh.
} 
DH-12, DH-13, DH-14, DH-15, DH-16 and DH-17) and three varieties (Protiva, Kanchan and Shatabdi) were grown in randomized complete block design (RCBD) with three replications at the experimental field laboratory of the Department of Genetics and Plant breeding, Bangladesh Agricultural University, Mymensingh, during the winter of 20052006. The plot size was $1.6 \mathrm{~m} 2.5 \mathrm{~m}$. The distance between two plots was $50 \mathrm{~cm}$. The spacing between rows and that of between plants in rows was $20 \mathrm{~cm}$ and $5 \mathrm{~cm}$, respectively. Fertilizers and manures were applied at the rates of 200, 150, 80, 50 and $600 \mathrm{~kg} / \mathrm{ha}$ of Urea, TSP, MOP, Gypsum and cowdung, respectively. Weeding was done when it became necessary. The crop was irrigated twice, one at the tillering stage and the other at grain filling stage. Data were collected from 10 random plants of the middle rows in each plot for days to maturity, plant height, spikes per plant, spike length, grains per spike, 100-grain weight and grain yield per plant. Data were subjected to analysis of Mahalanobis' $\mathrm{D}^{2}$ statistics. Intra-cluster and inter-cluster distance, cluster mean and contribution of each character to the divergence were estimated as suggested by Singh and Chaudhary (1985).

\section{RESULTS AND DISCUSSION}

The variation among the genotypes of $\mathrm{DH}$ lines and the check varieties was studied on multivariate scale using Mahalanobis' $\mathrm{D}^{2}$-statistics. Assuming the $\mathrm{D}^{2}$-values as $\chi^{2}$ it appears that there were significant variations among all the genotypes. Twenty genotypes were grouped into six clusters, which are presented in the Table 1. The clusters I and III were the largest, each containing five genotypes. The clusters VI, IV and II included four, three and two genotypes respectively. The cluster $\mathrm{V}$ included only one genotype. Average intra and inter cluster distance of six clusters are presented in the Table 2. The highest distance was obtained between the clusters I and V and it was followed by the distance between the clusters I and IV, II and V, III and V, V and VI. The distances between the clusters III and V, V and VI had the same value. It is general observation that the cluster I had higher distance from the rest. It suggests that the genotypes in the cluster I were distinctly different from others. The distance between the cluster III and VI was minimum followed by the distance between the clusters II and VI suggesting that genotypes belonging to these clusters were less diversified. Gartan and Mittal (2003) studied genetic divergence of 68 bread wheat genotypes and grouped them into 6 clusters. Gupta et al. (2002) constructed four clusters from 24 advanced lines of bread wheat and reported that the clusters I and III were highly divergent. Nimbalkar et al. (2002) studied genetic divergence of 24 cultivars and grouped them into 12 clusters. They observed highest and lowest intracluster distances in the clusters III and I, respectively. Bergale et al. (2001) grouped 50 bread wheat cultivars into 11 clusters.

Table 1. Distribution of 20 genotypes/ varieties/ lines of bread wheat in 6 clusters

\begin{tabular}{c|c|l}
\hline Cluster & No. genotypes & Genotypes \\
\hline I & 5 & DH-3, DH-4, DH-8, DH-10, DH-14 \\
II & 2 & DH-6, DH-16 \\
III & 5 & DH-2, DH-13, DH-15, DH-17, Shatabdi \\
IV & 3 & DH-9, DH-11, DH-12 \\
V & 1 & DH-5 \\
VI & 4 & DH-1, DH-7, Protiva, Kanchan \\
\hline
\end{tabular}


Table 2. Average intra and inter cluster distances $\left(D^{2}\right.$ and $\left.\sqrt{D^{2}}\right)$ in bread wheat

\begin{tabular}{|c|c|c|c|c|c|c|}
\hline Clusters & I & II & III & IV & V & VI \\
\hline I & $\begin{array}{l}12.234 \\
(3.497)\end{array}$ & $\begin{array}{c}13.26 \\
(3.641)\end{array}$ & $\begin{array}{c}12.98 \\
(3.602)\end{array}$ & $\begin{array}{c}22.69 \\
(4.763)\end{array}$ & $\begin{array}{c}33.08 \\
(5.751)\end{array}$ & $\begin{array}{c}14.07 \\
(3.750)\end{array}$ \\
\hline II & & $\begin{array}{l}11.87 \\
(3.445)\end{array}$ & $\begin{array}{c}5.40 \\
(2.323)\end{array}$ & $\begin{array}{c}11.22 \\
(3.349)\end{array}$ & $\begin{array}{c}22.03 \\
(4.693)\end{array}$ & $\begin{array}{c}3.60 \\
(1.897)\end{array}$ \\
\hline III & & & $\begin{array}{l}11.546 \\
(3.397)\end{array}$ & $\begin{array}{c}10.14 \\
(3.184)\end{array}$ & $\begin{array}{c}20.22 \\
(4.496)\end{array}$ & $\begin{array}{c}3.49 \\
(1.868)\end{array}$ \\
\hline IV & & & & $\begin{array}{l}13.296 \\
(3.646)\end{array}$ & $\begin{array}{l}11.59 \\
(3.404)\end{array}$ & $\begin{array}{c}9.39 \\
(3.064)\end{array}$ \\
\hline V & & & & & 0.00 & $\begin{array}{c}20.22 \\
(4.496)\end{array}$ \\
\hline VI & & & & & & $\begin{array}{l}10.620 \\
(3.258)\end{array}$ \\
\hline
\end{tabular}

The values on the diagonals (bold) are the intra-cluster and those on off-diagonals are the intercluster distance. The values in the parenthesis are $\sqrt{D^{2}}$.

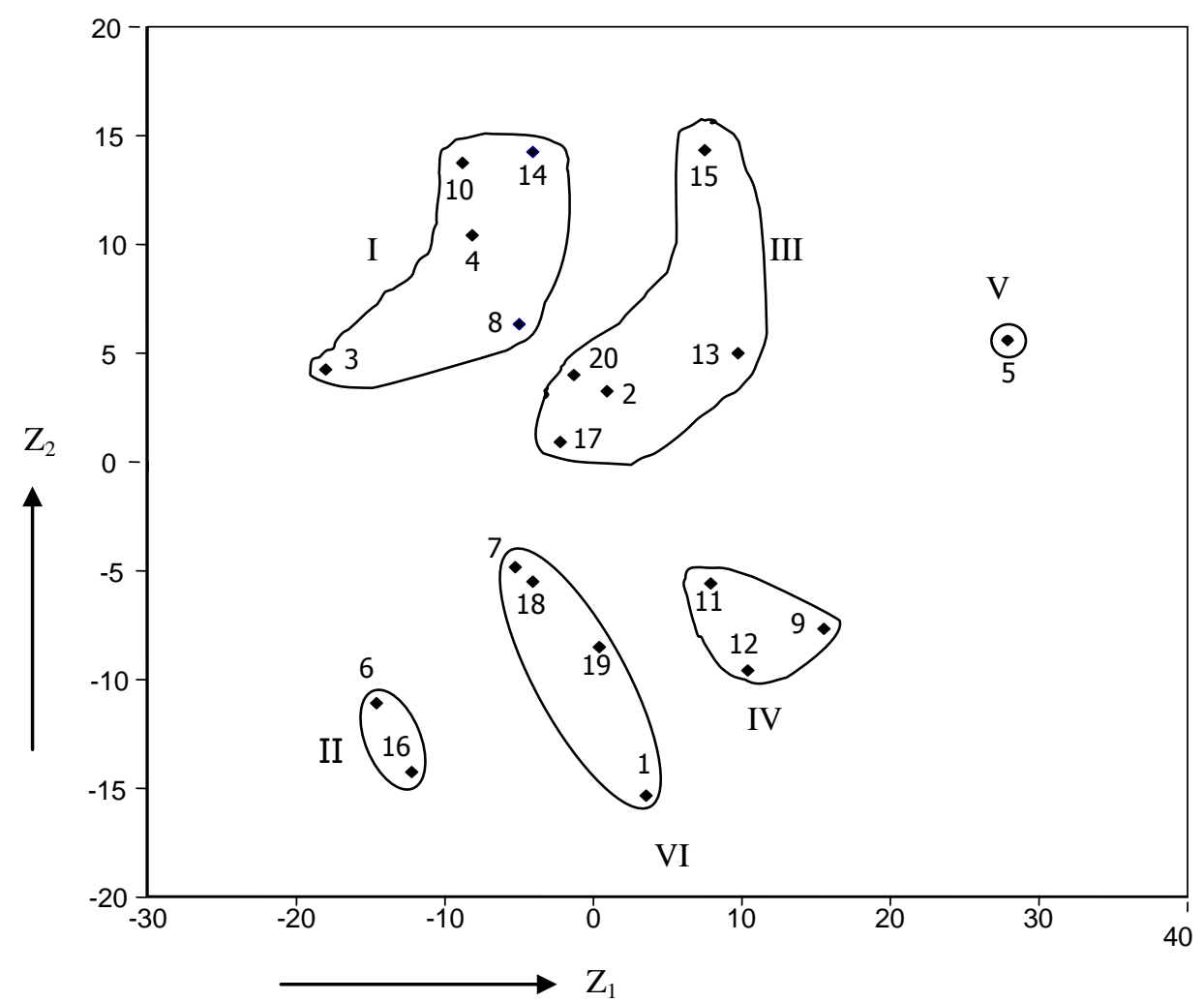

Fig 6. Scatter distribution of 20 bread wheat genotypes based on their principal components scores superimpose with clustering $(1 \ldots \ldots \ldots \ldots 20=$ Serial no. of the genotypes/lines) 
Principal Component Analysis (PCA) also helps in assessment of diversity in multivariate scales. In PCA the first two components were found to contribute $84.28 \%$ of the total variation. Therefore, scores obtained for the first two components were plotted against two main axes and then superimposed with clustering (Fig. 1). This clustering pattern confirmed the results obtained by $\mathrm{D}^{2}$-analysis.

Contributions of characters towards divergence were estimated through canonical variate analysis. In this method vectors or canonical roots was calculated to represent the genotypes in the graphical form (Rao, 1952). The coefficients pertaining to the different characters in the first two canonical roots are presented in the Table 3. From the positive absolute value of the two vectors, it revealed that grains per spike had the greatest contribution to genetic divergence. The negative values for the two vectors of days to maturity and spike length indicated the least responsibility of both the primary and secondary differentiations. However the positive absolute values of vector- 1 and negative absolute value for vector-2 for plant height indicated the responsibility of primary differentiation. On the contrary, the negative absolute values for vector- 1 and positive absolute values for vector-2 for the characters grain per spike, 100-grain weight and grain yield per plant indicated the responsibility of secondary differentiation. Elias and Shamsuddin (2000) studied genetic divergence and grouped 16 genotypes into six distinct clusters. Grain yield per square meter contributed maximum to the total divergence and followed by 100-grain weight, number of grains per spike. Suri and Sharma (1999) grouped 200 genotypes of wheat into sixteen clusters and reported that grain yield and tiller number per plant were major contributors towards genetic divergence with moderate contribution from 1000-grain weight, grains per spike and harvest index.

Table 3. Contribution of characters towards divergence in bread wheat

\begin{tabular}{lcc}
\hline Characters & Vector-1 & Vector-2 \\
\hline Days to maturity & -0.465 & -0.295 \\
Plant height & 0.006 & -0.378 \\
Spikes per plant & -0.485 & 0.024 \\
Spike length & -0.259 & -0.497 \\
Grains per spike & -0.053 & 0.615 \\
100-Grain weight & -0.475 & 0.070 \\
Grain yield per plant & -0.501 & 0.371 \\
\hline
\end{tabular}

Table 4. Cluster means for yield and yield contributing characters in bread wheat

\begin{tabular}{l|c|c|c|c|c|c}
\hline \multirow{2}{*}{ Characters } & \multicolumn{7}{c}{ Cluster } \\
\cline { 2 - 7 } & I & II & III & IV & V & VI \\
\hline Days to maturity & 101.27 & 96.33 & 104.93 & 103.66 & 103.00 & 108.83 \\
Plant height & 87.30 & 80.66 & 98.07 & 105.00 & 123.33 & 91.54 \\
Spikes per plant & 7.80 & 7.16 & 8.20 & 6.22 & 9.00 & 9.41 \\
Spike length & 9.60 & 9.25 & 10.00 & 10.17 & 9.00 & 10.92 \\
Grains per spike & 40.33 & 18.00 & 34.87 & 20.56 & 31.33 & 21.91 \\
100-Grain weight & 3.10 & 3.49 & 3.83 & 3.00 & 3.97 & 3.84 \\
Grain yield per plant & 2.47 & 1.54 & 2.56 & 1.25 & 2.29 & 2.50 \\
\hline
\end{tabular}


Mean values of cluster for yield and its different contributing characters are presented in the Table 4. It appears that the early maturing genotypes were included in the cluster II. The clusters IV and V included intermediate genotypes for maturity and late maturing genotypes were included in the cluster VI. The dwarf genotypes were included in the cluster II and the tall genotypes include in the cluster V. Maximum number of spike per plant were produced by the genotypes of the cluster VI, followed by the genotypes of the cluster V. The cluster IV contains genotypes which produced comparatively less number of spikes per plant. There was little variation among the cluster means for spike length. The genotypes of the cluster I produced maximum number of grains per spike, whereas the genotypes of the cluster II produced minimum number of grains per spike. There was very little variation among the cluster means for 100-grain weight. The highest yield per plant was produced by the genotypes of the cluster III and that of lowest yield was produced by the genotypes of the cluster IV. Considering all the characters it appears that the genotypes in the cluster III had good performance. The genotypes in this cluster had intermediate growth duration, intermediate plant height, higher 100-grain weight and the highest grain yield per plant. The results of the present study indicate that the cluster I and V, I and IV, II and V exhibited wide distance between them. Parental material selected from these clusters would give broader spectrum of variation when they are hybridized. Therefore, for wheat improvement program parental materials should be selected from these clusters.

\section{REFERENCES}

Bergale, S.; B. Mridulla, A. S. Holkar, K. N. Ruwalli and S. V. S. Prasad. 2001. Genetic variability, diversity and association of quantitative traits with grain yield in bread wheat (Triticum aestivum L.). Madras Agril. J. 88(7-9): 457-461.

Elias, M. A. and A. K. M. Shamsuddin. 2000. Genetic divergence in bread wheat (Triticum aestivum L.) for source sink characters. Bangladesh J. Pl. Breed. Genet. 13(2): 1924.

Gartan, S. L. and R. K. Mittal. 2003. Genetic divergence in bread wheat. Crop Improv. 30(2): 185-188.

Gupta, R. S., D. K. Tiwari, S. S. Deol and R. P. Singh. 2002. Genetic divergence in bread wheat (Triticum aestivum L. Em Thell). New Botanist. 529:1-4.

Mahalanobis, P. C. 1936. On the generalized distance in statistics. Nat. Inst. Sci. Ind. B. Z : 49-55.

Nimbalkar, C.A. P. A. Navale and A.B. Biradar. 2002. Generalized $D^{2}$ and genetic diversity in wheat. J. Maharashtra Agril. Univ. 27(1): 43-45.

Rao, C.R. 1952. Advance statistical method in biometrical research. Ednl. John Willey and Sons, New York.

Singh R. K. and B. D. Chaudhary. 1985. Biometrical methods in quantitative genetic analysis. Kalyani Publishers, New Delhi. pp. 225-252.

Suri, V. and S. C. Sharma. 1999. Genetic diversity in relation to number of clusters in wheat (Triticum aestivum L.). Crop Improv. 26(2): 208-215. 